\title{
Predictors of urinary incontinence in community- dwelling frail older adults with diabetes mellitus in a cross-sectional study
}

Amy Hsu ${ }^{1,2^{*}}$, Jessamyn Conell-Price ${ }^{3}$, Irena Stijacic Cenzer ${ }^{2,4}$, Catherine Eng ${ }^{2,5}$, Alison J Huang ${ }^{6}$, Kathy Rice-Trumble ${ }^{5}$ and Sei J Lee L,7 $^{2,7}$

\begin{abstract}
Background: Diabetes mellitus is a potent risk factor for urinary incontinence. Previous studies of incontinence in patients with diabetes have focused on younger, healthier patients. Our objective was to characterize risk factors for urinary incontinence among frail older adults with diabetes mellitus in a real-world clinical setting.

Methods: We performed a cross-sectional analysis on enrollees at On Lok (the original Program for All-Inclusive Care of the Elderly) between October 2004 and December 2010. Enrollees were community-dwelling, nursing home-eligible older adults with diabetes mellitus $(N=447)$. Our outcome was urinary incontinence measures ( $n=2602$ ) assessed every 6 months as "never incontinent", "seldom incontinent" (occurring less than once per week), or "often incontinent" (occurring more than once per week). Urinary incontinence was dichotomized ("never" versus "seldom" and "often" incontinent). We performed multivariate mixed effects logistic regression analysis with demographic (age, gender and ethnicity), geriatric (dependence on others for ambulation or transferring; cognitive impairment), diabetes-related factors (hemoglobin A1c level; use of insulin and other glucose-lowering medications; presence of renal, ophthalmologic, neurological and peripheral vascular complications), depressive symptoms and diuretic use.
\end{abstract}

Results: The majority of participants were 75 years or older (72\%), Asian (65\%) and female (66\%). Demographic factors independently associated with incontinence included older age (OR for age >85, 3.13, 95\% Cl: 2.15-4.56; Reference: Age <75) and African American or other race (OR 2.12, 95\% Cl: 1.14-3.93; Reference: Asian). Geriatric factors included: dependence on others for ambulation (OR 1.48, 95\% Cl: 1.19-1.84) and transferring (OR 2.02, 95\% Cl: 1.58-2.58) and being cognitively impaired (OR 1.41,95\% Cl: 1.15-1.73). Diabetes-related factors associated included use of insulin (OR 2.62, 95\% Cl: 1.67-4.13) and oral glucose-lowering agents (OR 1.81, 95\% Cl: 1.33-2.45). Urinary incontinence was not associated with gender, hemoglobin A1c level or depressive symptoms.

Conclusions: Geriatric factors such as the inability to ambulate or transfer independently are important predictors of urinary incontinence among frail older adults with diabetes mellitus. Clinicians should address mobility and cognitive impairment as much as diabetes-related factors in their assessment of urinary incontinence in this population.

Keywords: Urinary incontinence, Frail older adults, Diabetes mellitus

\footnotetext{
* Correspondence: Amy.Hsu@ucsf.edu

'VA Quality Scholars Fellow, Geriatrics and Extended Care, San Francisco VA

Medical Center, 4150 Clement Street, 181G, San Francisco, CA 94122, USA

2Division of Geriatrics, University of California at San Francisco, San Francisco,

CA, USA

Full list of author information is available at the end of the article
}

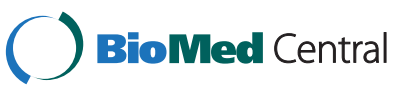

(c) 2014 Hsu et al.; licensee BioMed Central Ltd. This is an Open Access article distributed under the terms of the Creative Commons Attribution License (http://creativecommons.org/licenses/by/4.0), which permits unrestricted use, distribution, and reproduction in any medium, provided the original work is properly credited. The Creative Commons Public Domain Dedication waiver (http://creativecommons.org/publicdomain/zero/1.0/) applies to the data made available in this article, unless otherwise stated. 


\section{Background}

Urinary incontinence (UI) is common among frail older adults [1-4] and is associated with substantial morbidity and mortality. UI significantly decreases quality of life [5-8], increases the risk of depression [5,9], disability [5,6], social isolation [6], loss of dignity [8] and poor self-rated health $[5,10]$. Further, it is associated with increases in adverse outcomes, including falls $[11,12]$, fractures [11], hospitalization [13], nursing home admission [13] and has been linked with mortality [14].

Diabetes is a potent risk factor for UI, increasing both the prevalence [15-19] and severity [20] of UI. Previous research suggests that $10-50 \%$ of older adults with diabetes experience UI [21-23]. Middle-aged and older ambulatory women with diabetes mellitus have increased odds of having UI compared to women without diabetes [16-20]. Women with diabetes mellitus were also twice as likely to develop more severe UI with enough leakage to wet outer clothing compared to women without diabetes [20]. Although frail community-dwelling older adults with diabetes represent a large, growing population at high risk for UI, to our knowledge, no studies have examined the risk factors for UI in this population. Thus, we sought to characterize risk factors for UI among nursing homeeligible, community dwelling frail older adults with diabetes mellitus in a real-world setting.

\section{Methods}

\section{Participants}

We studied all On Lok enrollees diagnosed with diabetes mellitus between October 2004 and December 2010 (N = 447 participants with $\mathrm{n}=2602$ UI measurements). On Lok, the original model for Programs for All-inclusive Care for the Elderly (PACE), requires enrollees to be nursing home-eligible, indicating that the participant requires care with full-time supervision of a licensed nurse. On Lok helps nursing home-eligible enrollees remain in the community by providing and coordinating healthcare services, including primary and specialist physician services, adult day health care, home care, hospital care, post-acute rehabilitation care and custodial nursing home care. On Lok provides enrollees with transportation between home and PACE centers where meals, medication management, help with bathing or showering and recreational activities are provided. Further, On Lok centers have physical and occupational therapists, social workers, nurses and physicians on-site. Each enrollee receives a comprehensive health assessment (medical evaluation with assessment of function and geriatric syndromes) upon enrollment and every 6 months thereafter by physicians, nurses, therapists and social workers.

Enrollees were eligible for our study if they were enrolled in On Lok during the study period and had a diagnosis of diabetes mellitus on a glucose lowering medication or a hemoglobin A1c (HbA1c) level greater than 6.5\% (Figure 1). Diabetes diagnosis was determined according to the International Classification of Diseases, Ninth Revision (ICD-9) code, 250.xx.

We initially identified 460 (N) On Lok enrollees with 2783 (n) UI measurements. UI measurements were excluded from the analysis if enrollees had end-stage renal disease on dialysis $(N=6, n=59)$, were receiving end-oflife care $(\mathrm{N}=6, \mathrm{n}=112)$ or had a urinary catheter $(\mathrm{N}=1$, $\mathrm{n}=10$ ). These exclusion criteria led to our final analytic cohort of 447 enrollees with 2602 UI measurements. All data were extracted from electronic medical records. The Committee on Human Research at the University of California San Francisco and the San Francisco VA Research and Development Committee approved this study. Further, they found that this study satisfied federal criteria for waiving informed consent since 1) it poses minimal risks to participants, 2) it would not be practicable to obtain informed consent and 3) participants rights are not adversely affected by waiving informed consent.

To capture the dynamic nature of diabetes and UI in this population, our unit of analysis was measures of urinary incontinence. Thus, a patient who was in our study for 9 months would contribute two UI measurements: the initial admission assessment and the subsequent 6 month follow-up assessment. This allowed us to explore whether risk factors that change over time such as insulin use or HbA1c levels affect incontinence.

\section{Measures: outcome}

The primary outcome was urinary incontinence, evaluated during semi-annual comprehensive health assessments. A nurse or therapist determined the presence and frequency of UI by conducting interviews with enrollees and corroborating with family caregivers and home care aides. Nurses and therapists were trained to code UI occurring less than once a week as "seldom incontinent" and UI occurring more than once per week as "often incontinent".

We compared measures of "never incontinent" to the combined measure of "seldom incontinent" and "often incontinent". To explore whether some factors were associated with more severe incontinence, we also compared "never incontinent" to "often incontinent".

\section{Measures: potential predictors}

We examined a wide range of potential factors that may be associated with urinary incontinence. Specifically, we examined demographic factors including age, gender and race/ethnicity. We examined geriatric factors including dependence in ambulation, dependence in transferring and cognitive impairment. Ambulation and transferring was assessed by a nurse who made an in-person determination of whether the individual was independent, required supervision, required assistance, was dependent on others 


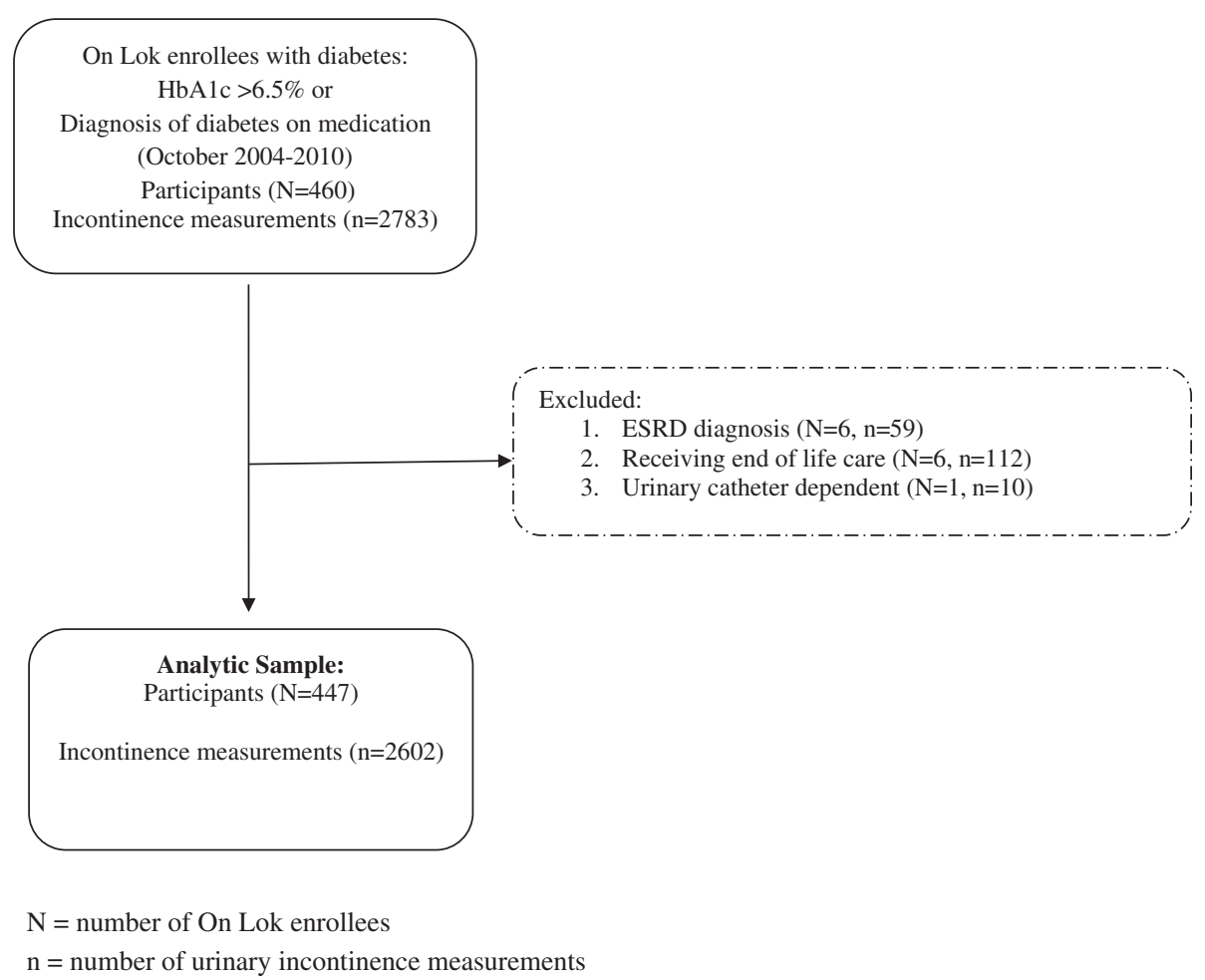

Figure 1 Inclusion and exclusion criteria for participants and measurements; ESRD = End-stage renal disease.

or non-ambulatory. All levels except for independent were categorized as "dependent." Participants with a Mental Status Questionnaire (MSQ) score greater than 4 were considered to have cognitive impairment. Participants without MSQ scores but had an ICD-9 diagnosis of dementia were also considered to have cognitive impairment.

We examined diabetes-related factors including the use of glucose lowering medications, HbA1c levels, and diabetes-related complications such as renal or ophthalmologic complications, peripheral vascular disease, and neurological disease (through ICD-9 codes). To determine the HbA1c level on the day of urinary incontinence assessment, we interpolated HbA1c values, assuming that the HbA1c changes in a linear fashion between 2 measured values. For example, if the first measured HbA1c value is $7.0 \%$ and the next measured value 100 days later is $8.0 \%$, the interpolated HbA1c value is $7.1 \%$ on Day $10,7.2 \%$ on Day 20, etc. We also examined whether depressive symptoms and diuretic use was associated with urinary incontinence. Presence of depressive symptoms was defined by a short Geriatric Depression Scale score greater than 9.

Several other factors were considered, but were not included in the final analysis due to a low number of participants and measurements (less than 10\%) with these risk factors. These included: obesity, benign prostatic hypertrophy, prostate cancer (determined using ICD-9 codes) and use of a urinary antispasmodic agent.

\section{Statistical analysis}

Subjects with and without incontinence were characterized using descriptive bivariate statistics. We used ANOVA to compare the means of continuous variables (age and HbA1c level) and Chi-square tests to compare categorical variables. We performed multivariate analyses to identify independent risk factors for urinary incontinence using mixed effects logistic regression to account for clustering of incontinence measurements by participant. We adjusted for age, gender, Asian race, dependence in transferring and ambulating, cognitive impairment, use of thiazide or loop diuretics, depression, diabetic medication use, and diabetic complications (renal, ophthalmologic, peripheral vascular, and neurological). All analyses were performed using Stata MP (version 10.1, StataCorp, College Station, TX) and SAS (version 9.2, SAS System of Windows, SAS Institute Inc., Cary, NC).

\section{Results}

\section{Characteristics of the participants}

Table 1 shows the characteristics of the participants at initial assessment by level of urinary incontinence. The overall prevalence of UI was $44 \%$ at baseline. The majority of participants were 75 years or older with a high proportion of female and Asian enrollees. Participants had an average of 5 assessments (range 1-19). At the first assessment 56\% were "never incontinent", $28 \%$ were 
Table 1 Baseline characteristics of participants by urinary incontinence status, $\mathrm{N}=\mathbf{4 4 7}$

\begin{tabular}{|c|c|c|c|c|c|}
\hline Characteristic & Number of persons, $\mathrm{N}$ & Never incontinent, $\mathrm{N}$ & Seldom incontinent, $\mathrm{N}$ & Often incontinent, $\mathrm{N}$ & p-value \\
\hline Total persons & 447 & $249(56 \%)$ & $125(28 \%)$ & $73(16 \%)$ & \\
\hline Mean Age & & $78( \pm 8.2)$ & $80( \pm 8.1)$ & $81( \pm 8.0)$ & 0.961 \\
\hline \multicolumn{6}{|l|}{ Age categories } \\
\hline$<75$ & 127 & $88(70 \%)$ & $27(21 \%)$ & $12(9 \%)$ & 0.003 \\
\hline $75-80$ & 101 & $52(52 \%)$ & $34(34 \%)$ & $15(15 \%)$ & \\
\hline $80-85$ & 118 & $64(54 \%)$ & $28(24 \%)$ & $26(22 \%)$ & \\
\hline$>85$ & 101 & $45(56 \%)$ & $36(36 \%)$ & $20(16 \%)$ & \\
\hline \multicolumn{6}{|l|}{ Race/Ethnicity } \\
\hline Asian & 290 & $168(58 \%)$ & $73(25 \%)$ & 49 (17\%) & 0.364 \\
\hline White & 58 & $25(43 \%)$ & $21(36 \%)$ & $12(21 \%)$ & \\
\hline African & 35 & 19 (54\%) & $11(31 \%)$ & $5(15 \%)$ & \\
\hline \multicolumn{6}{|c|}{ American/Other } \\
\hline Latino & 64 & 37 (58\%) & $20(31 \%)$ & $7(11 \%)$ & \\
\hline \multicolumn{6}{|l|}{ Gender } \\
\hline Male & 154 & $98(64 \%)$ & $40(26 \%)$ & $16(10 \%)$ & 0.018 \\
\hline Female & 293 & 151 (51\%) & $85(29 \%)$ & 57 (19\%) & \\
\hline \multicolumn{6}{|l|}{ Ambulation $^{a}$} \\
\hline Independent & 254 & $173(68 \%)$ & $61(24 \%)$ & $20(8 \%)$ & 0.000 \\
\hline Dependent ${ }^{\mathrm{b}}$ & 188 & 75 (40\%) & $63(34 \%)$ & $50(27 \%)$ & \\
\hline \multicolumn{6}{|l|}{ Transferring $^{c}$} \\
\hline Independent & 317 & $204(64 \%)$ & $82(26 \%)$ & $31(10 \%)$ & 0.000 \\
\hline Dependent ${ }^{\mathrm{b}}$ & 127 & $45(35 \%)$ & $42(33 \%)$ & $40(32 \%)$ & \\
\hline \multicolumn{6}{|c|}{ Cognitive Impairment } \\
\hline Absent & 228 & $184(64 \%)$ & $71(25 \%)$ & $33(11 \%)$ & 0.000 \\
\hline Present & 159 & $65(41 \%)$ & $54(34 \%)$ & $40(25 \%)$ & \\
\hline
\end{tabular}

\section{Other Medications}

Loop or Thiazide

Diuretic Use

$\begin{array}{ll}\text { No } & 336 \\ \text { Yes } & 111\end{array}$

$188(56 \%)$

$61(55 \%)$

Other factors

Depressive $^{d}$

Symptoms

Absent
Present
Hemoglobin A1c
Level

Mean $(95 \% \mathrm{Cl})$

$<7$
$7-7.9$
$8-8.9$
$\geq 9$

$\geq 9$
110

163

152

69

63
187 (57\%)

$59(54 \%)$

$7.7(7.5-7.9)$
$87(53 \%)$
$82(54 \%)$
$46(67 \%)$
$34(54 \%)$

87 (26\%)

37 (34\%)

7.6 (7.3-7.8)

53 (33\%)

$42(28 \%)$

13 (19\%)

17 (27\%)
$57(17 \%)$

$16(14 \%)$

0.679

34 (31\%)

55 (17\%)

0.287

$14(13 \%)$

$$
\begin{gathered}
7.7(7.4-8.0) \\
23(14 \%) \\
28(18 \%) \\
10(14 \%)
\end{gathered}
$$$$
12(19 \%)
$$

0.645

0.382 
Table 1 Baseline characteristics of participants by urinary incontinence status, $\mathbf{N}=447$ (Continued)

\begin{tabular}{|c|c|c|c|c|c|}
\hline \multicolumn{6}{|c|}{ Diabetes Medications } \\
\hline None & 272 & 157 (58\%) & $70(38 \%)$ & $45(17 \%)$ & \multirow[t]{3}{*}{0.527} \\
\hline Oral Medications & 133 & 73 (55\%) & 39 (29\%) & $21(16 \%)$ & \\
\hline Insulin & 42 & $19(45 \%)$ & $16(38 \%)$ & $7(17 \%)$ & \\
\hline \multicolumn{6}{|l|}{$\begin{array}{l}\text { Diabetes } \\
\text { Complications }\end{array}$} \\
\hline \multicolumn{6}{|l|}{ Renal } \\
\hline Absent & 200 & $106(53 \%)$ & 57 (29\%) & 37 (19\%) & \multirow[t]{2}{*}{0.460} \\
\hline Present & 247 & $143(58 \%)$ & $68(28 \%)$ & $36(15 \%)$ & \\
\hline \multicolumn{6}{|l|}{ Ophthalmologic } \\
\hline Absent & 299 & $165(55 \%)$ & $80(27 \%)$ & $54(18 \%)$ & \multirow[t]{2}{*}{0.338} \\
\hline Present & 148 & $84(57 \%)$ & 45 (30\%) & 19 (13\%) & \\
\hline \multicolumn{6}{|l|}{ Peripheral vascular } \\
\hline Absent & 384 & $216(56 \%)$ & 107 (28\%) & $61(16 \%)$ & \multirow[t]{2}{*}{0.784} \\
\hline Present & 63 & $33(52 \%)$ & 18 (29\%) & 12 (19\%) & \\
\hline \multicolumn{6}{|l|}{ Neurological } \\
\hline Absent & 336 & $180(54 \%)$ & 103 (31\%) & $53(16 \%)$ & \multirow[t]{2}{*}{0.088} \\
\hline Present & 111 & 69 (62\%) & $22(20 \%)$ & $20(18 \%)$ & \\
\hline
\end{tabular}

${ }^{\mathrm{a}} \mathrm{N}=5$ with missing observations.

${ }^{\mathrm{b}}$ Partially or fully dependent.

${ }^{\mathrm{c}} \mathrm{N}=3$ with missing observations.

${ }^{\mathrm{d}} \mathrm{N}=6$ with missing observations.

"seldom incontinent", and 16\% were "often incontinent". Participants were frail older adults with complex medical issues. Forty-two percent were dependent with ambulation and $36 \%$ had cognitive impairment. Severe urinary incontinence was more common at baseline in older adults with dependence in ambulation and transferring and cognitive impairment. Diuretic use was common in our study population at $25 \%$. Depressive symptoms were present in $25 \%$ of participants. Depressive symptoms were present in $57 \%$ of those with measurements of "often incontinent" but in fewer than 30\% of those with "never incontinent" or "seldom incontinent" measures. Participants had appropriately controlled diabetes according the American Geriatrics Society guidelines [24], with $70 \%$ of participants with HbA1c of less than $8 \%$ at the first visit within our study. However, forty-eight percent of participants had renal complications related to diabetes while other diabetes-related complications were less common.

\section{Independent predictors of incontinence}

Many non-diabetes factors were strongly associated with urinary incontinence (Table 2). Demographic factors (increasing age and African American or other and White race) were associated with urinary incontinence. Although female gender was associated with incontinence in the bivariate analysis, gender was not an independent predictor after adjustment. Geriatric factors were also strongly associated with urinary incontinence. Partial or full dependence with ambulation or transferring were both associated with urinary incontinence with the odds ratio for transferring remaining over 2 after adjustment. Two factors commonly associated with urinary incontinence, diuretic use and presence of depressive symptoms, were not associated with urinary incontinence in this study.

Several diabetes-related factors in the model were significantly associated with urinary incontinence. The strongest association was the use of insulin followed by use of oral glucose-lowering agents. HbA1c level was not found to be associated with increased odds of UI.

The sensitivity analysis performed by comparing "never incontinent" with "often incontinent" showed similar results. However, peripheral vascular disease was found to be independently associated with being "often incontinent" (OR 2.33; 95\% CI: 1.35, 4.02) but not when "seldom" was combined with "often incontinent" (OR 1.31; 95\% CI: $0.81,2.10)$. A second sensitivity analysis performed using ordinal logistic regression with 3 outcome categories (never, seldom and often incontinent) showed that dependence in ambulation (OR 1.61; 95\% CI: 1.142.27), transferring (OR 3.32; 95\% CI: 2.28-4.84) and 
Table 2 Multivariate analysis of factors associated with urinary incontinence

\begin{tabular}{lllll}
\hline Characteristic & \multicolumn{2}{c}{ Never vs. Seldom/often incontinent } & Never vs. often incontinent \\
\cline { 2 - 3 } & Unadjusted OR $(95 \% \mathrm{Cl})$ & Adjusted $^{\mathrm{a}}$ OR $(95 \% \mathrm{Cl})$ & Unadjusted OR (95\% Cl) & Adjusted ${ }^{\mathrm{a}}$ OR (95\% Cl) \\
\hline \multicolumn{3}{c}{ Non-diabetes related factors } \\
\hline
\end{tabular}

\section{Demographics}

Age

$\begin{array}{ll}<75 & 1.00 \text { (Reference) } \\ 75-80 & 1.79(1.37-2.35) \\ 80-85 & 2.61(1.92-3.56) \\ >85 & 4.75(3.36-6.71)\end{array}$

\section{Race/Ethnicity}

Asian
White
African
American/Other

Gender

$\begin{array}{lr}\text { Male } & 1.00 \text { (Reference) } \\ \text { Female } & 1.55(1.13-2.14)\end{array}$

\section{Geriatric factors}

\section{Ambulation}

$$
\text { Independent }
$$

\section{Transferring}

Independent

Dependent ${ }^{\mathrm{b}}$

\section{Cognitive Impairment}

$\begin{array}{ll}\text { Absent } & 1.00 \text { (Reference) } \\ \text { Present } & 1.67(1.40-1.99)\end{array}$

\section{Other Medications}

Loop or Thiazide Diuretic

$\begin{array}{ll}\text { No } & 1.00 \text { (Reference) } \\ \text { Yes } & 1.24 \text { (0.93-1.65) }\end{array}$

\section{Other factors}

Depressive Symptoms

\begin{tabular}{lcc}
$\begin{array}{l}\text { Absent } \\
\text { Present }\end{array}$ & 1.00 (Reference) & 1.00 (Reference) \\
& $0.91(0.64-1.29)$ & 0.97 (0.67-1.41) \\
\hline $\begin{array}{l}\text { Hemoglobin A1c Level } \\
<7\end{array}$ & 1.05 (0.89-1.23) & 1.01 (0.84-1.22) \\
$7-7.9^{c}$ & 1.00 (Reference) & 1.00 (Reference) \\
$8-8.9$ & 0.76 (0.63-0.91) & $0.81(0.65-1.01)$ \\
$\geq 9$ & $0.69(0.55-0.87)$ & $0.85(0.65-1.11)$
\end{tabular}

$$
\begin{aligned}
& 1.00 \text { (Reference) } \\
& 1.57(1.17-2.11) \\
& 2.11(1.51-2.95) \\
& 3.13(2.15-4.56)
\end{aligned}
$$

1.00 (Reference)

$2.15(1.28-3.59)$

$2.12(1.14-3.93)$

$1.08(0.67-1.75)$

1.00 (Reference)

$1.27(0.91-1.78)$

1.00(Reference)

1.48 (1.19-1.84)

1.00 (Reference)

$2.02(1.58-2.58)$

1.00 (Reference)

$1.41(1.15-1.73)$

$$
1.00 \text { (Reference) }
$$$$
0.81(0.57-1.15)
$$

.00 (Reference)

$0.94(0.66-1.36)$

1.00 (Reference)

$0.64(0.39-1.04)$
1.00 (Reference)
$1.18(0.73-1.89)$
$2.35(1.44-3.84)$
$2.29(1.34-3.92)$

1.00 (Reference)

$1.80(0.93-3.48)$

$2.43(1.16-5.08)$

$0.91(0.49-1.70)$

1.00 (Reference)

$0.95(0.61-1.49)$

1.00 (Reference)

$1.92(1.37-2.67)$

1.00 (Reference)

1.00 (Reference)

$1.85(1.39-2.46)$

$1.71(1.37-2.13) \quad 1.85(1.39-2.46)$

$2.78(1.99-3.89)$

1.00 (Reference)

1.00 (Reference)

$0.78(0.48-1.25)$

0.75 (0.45-1.23)

\section{ctors}


Table 2 Multivariate analysis of factors associated with urinary incontinence (Continued)

\begin{tabular}{|c|c|c|c|c|}
\hline \multicolumn{5}{|c|}{ Diabetes Medications } \\
\hline None & 1.00 (Reference) & 1.00 (Reference) & 1.00 (Reference) & 1.00 (Reference) \\
\hline Oral Medications & $1.66(1.30-2.13)$ & $1.81(1.33-2.45)$ & $1.50(1.11-2.03)$ & $1.79(1.17-2.75)$ \\
\hline Insulin & $2.30(1.58-3.37)$ & $2.62(1.67-4.13)$ & $2.33(1.53-3.54)$ & $3.41(1.88-6.21)$ \\
\hline \multicolumn{5}{|c|}{ Diabetes Complications } \\
\hline \multicolumn{5}{|l|}{ Renal } \\
\hline Absent & 1.00 (Reference) & 1.00 (Reference) & 1.00 (Reference) & 1.00 (Reference) \\
\hline Present & $0.93(0.68-1.26)$ & $0.95(0.68-1.33)$ & $0.76(0.51-1.13)$ & $0.73(0.46-1.14)$ \\
\hline \multicolumn{5}{|l|}{ Ophthalmologic } \\
\hline Absent & 1.00 (Reference) & 1.00 (Reference) & 1.00 (Reference) & 1.00 (Reference) \\
\hline Present & $0.82(0.60-1.13)$ & $1.00(0.71-1.43)$ & $0.70(0.46-1.09)$ & $0.68(0.42-1.10)$ \\
\hline \multicolumn{5}{|l|}{ Peripheral vascular } \\
\hline Absent & 1.00 (Reference) & 1.00 (Reference) & 1.00 (Reference) & 1.00 (Reference) \\
\hline Present & $1.68(1.08-2.61)$ & $1.31(0.81-2.10)$ & $2.30(1.38-3.83)$ & $2.33(1.35-4.02)$ \\
\hline \multicolumn{5}{|l|}{ Neurological } \\
\hline Absent & 1.00 (Reference) & 1.00 (Reference) & 1.00 (Reference) & 1.00 (Reference) \\
\hline Present & $0.72(0.51-1.02)$ & $0.73(0.49-1.08)$ & $1.05(0.68-1.65)$ & $1.43(0.87-2.36)$ \\
\hline
\end{tabular}

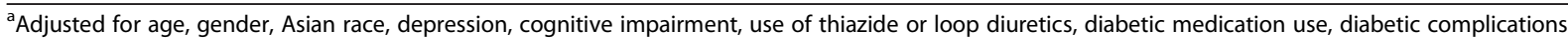
(neurological, renal, ophthalmologic, peripheral vascular, other), and dependence in transferring and/or ambulating.

${ }^{\mathrm{b}}$ Partially or fully dependent.

"Hemoglobin A1c level of $7 \%$ to $7.9 \%$ was used as the reference since the AGS "Guideline for improving the care of older persons with diabetes mellitus" recommends $<8 \%$ as appropriate target for glycemic control for "frail elders with limited life expectancy [24]".

presence of cognitive impairment (OR 1.73; 95\% CI: 1.29-2.32) continued to be statistically significantly correlated with urinary incontinence. The differences were that the age group of $75-80$ years old (OR 1.34; 95\% CI: 0.86-2.1), White race (OR 1.54; 95\% CI: 0.93-2.58), the use of oral glucose-lowering agents (OR 1.21, 95\% CI: $0.8-1.82$ ) and insulin (OR 1.48; 95\% CI: 0.81-2.68) were no longer statistically significantly associated with urinary incontinence. Having peripheral vascular disease was found to be statistically significant (OR 1.89, 95\% CI: 1.1-3.26).

\section{Discussion}

Among community-dwelling, nursing home-eligible frail older adults with diabetes mellitus, we found that risk factors common to all older adults were as important as diabetes-related factors in predicting UI. Specifically we found that older age, dependence on others for ambulation or transferring and cognitive impairment were all independent predictors for urinary incontinence. In contrast, among the diabetes-related factors we examined, only the use of diabetes medications were independent risk factors for urinary incontinence.

We found that three factors that are often invoked as potentially important risk factors were not associated with UI among our cohort of nursing home-eligible, community-dwelling older adults. First, diuretic use has been proposed as a risk factor since the use of these medications may increase the volume of urine and worsen UI [25] and the association may be specific to those with uninhibited detrusor contractions [26]. We did not detect a significant association between diuretic use and UI after adjustment for other potential risk factors. Previous studies that found an association between diuretic use and UI focused on younger women [25] or on those using high doses of loop diuretics [27]. Thus, our findings suggest that the type and dose of diuretic may be important factors in the diuretic-UI association.

Second, poor glycemic control has been proposed as a risk factor, since hyperglycemia can lead to both glycosuria and neuropathy, both of which may exacerbate UI [28-30]. We found no association between HbA1c level and UI. Previous studies have also shown a lack of association between HbA1c level and UI [31,32]. Our results suggest that improving glycemic control to HbA1c $<9 \%$ may not lead to substantial improvements in UI. Since both HbA1c levels and diuretic use were not associated with UI, urine volume may not be as important a mechanism for UI in frail, community-dwelling older adults with diabetes.

Lastly, our study did not find an association between UI and depressive symptoms. Two reasons may account for the absence of an association. First, prior studies have been performed in different populations and used different tool to measure depressive symptoms [5]. Second, depression may be mediated by functional limitations, 
which other studies have not controlled for [9]. Improvement in physical performance has also been associated with lower rates of incident UI [33].

Most previous research on UI in older adults has either focused on nursing home residents or healthier, ambulatory older adults residing in the community. Research among the nursing home population has shown high prevalence of UI from 65\% [6] to 70\% [3] and increased odds of UI in African Americans [3]. Among older adults residing in the community, prior research has shown that the risk of UI increases with age [1,5], impaired mobility $[1,34]$, greater disability $[5,35]$ and depressive symptoms $[5,9]$. Although PACE enrollees reside in the community, they are nursing home-eligible and have a high burden of comorbid medical conditions and functional limitations. Thus, PACE enrollees represent an intermediate population between community dwelling older adults and nursing home residents. Our results reflect this, with an overall prevalence of $44 \%$ that is between previous estimates of community-dwelling and nursing home residents.

Few previous studies have focused on UI in communitydwelling, nursing home-eligible populations with diabetes. Khatusky and colleagues examined UI in a general PACE population but relied on annual enrollee survey data to measure incontinence, rather than using clinical assessments [7]. While there are many studies that show that diabetes mellitus is an important risk factor for UI in adult populations [16-18,20,34], our study shows that in a frail older adult, PACE enrolled population, factors that affect all frail older adults, such as functional limitations, may be as important in assessing UI as diabetes-related factors.

Our study benefits from the inclusion of communitydwelling frail, older adults with diabetes mellitus who are eligible for nursing home admission and the evaluation of a wide array of both geriatric and diabetesrelated factors. However, several limitations should be considered when interpreting our results. First, our UI measurement was based on clinician assessment and categorized together all enrollees with at least weekly UI. Thus we were not able to distinguish specific factors that may lead to severe UI that occurs more frequently than daily. However, clinician assessment reflects real-world evaluation of UI where objective measurements are not often practical or possible. Second, we did not examine participants' cognitive status with cognitive testing, but used diagnoses of cognitive impairment made by clinicians. However, On Lok clinicians care for many cognitively impaired older adults [36] and are likely to be more experienced in diagnosing cognitive impairment than most clinicians. Third, due to low prevalence of obesity, benign prostatic hypertrophy, prostate cancer and use of urinary antispasmodic agents, we have limited power to detect potential confounding by these factors in our study. Lastly, our study consisted of a large proportion of participants of Asian ethnicity, which may not be generalizable to all community-dwelling nursing home-eligible older adults.

\section{Conclusions}

In conclusion, our findings highlight the complex nature of UI in frail older adults with diabetes. Like all geriatric syndromes, UI is rarely due to a single disease process; rather, it is the result of multiple factors. Thus, clinicians caring for frail older adults with diabetes should address mobility and cognitive impairment as much as glycemic control when managing UI. Further studies testing the relative efficacy of interventions that target UI risk factors are needed to determine how best to manage UI in this vulnerable population.

\section{Abbreviations}

UI: Urinary incontinence; PACE: Programs for all-inclusive care for the elderly; HbA1c: Hemoglobin A1c; MSQ: Mental status questionnaire: ICD-9: International classification of diseases, ninth revision.

\section{Competing interests}

The authors declare that they have no competing interests.

\section{Author contributions}

$\mathrm{AH}$ participated in the design of the study, interpretation of data and preparation of manuscript. JCP participated in the design of the study, interpretation of data and preparation of manuscript. ISC performed the statistical analysis of the data. CE participated in the design of the study and the acquisition of subjects and data. AJH performed critical revisions of the manuscript. KRT participated in the acquisition of subjects and data. SJL participated in the design of the study, interpretation of data and preparation of manuscript. All authors have read and approved the final manuscript.

\section{Acknowledgements}

This material is the result of work supported with resources and the use of facilities at the San Francisco VA Medical Center.

Dr. Sei Lee's effort was supported by the Beeson Career Development Award (K23AG040779) funded by the National Institution on Aging and the American Federation of Aging Research.

The sponsors had no role in the design, execution, analysis and interpretation of the study. The sponsors had no role in the preparation, review or approval of the manuscript for publication.

\section{Author details}

${ }^{1}$ VA Quality Scholars Fellow, Geriatrics and Extended Care, San Francisco VA Medical Center, 4150 Clement Street, 181G, San Francisco, CA 94122, USA

${ }^{2}$ Division of Geriatrics, University of California at San Francisco, San Francisco, CA, USA. ${ }^{3}$ University of California at San Francisco, San Francisco, CA, USA. ${ }^{4}$ Geriatrics and Extended Care, San Francisco VA Medical Center, San Francisco, CA, USA. ${ }^{5}$ On Lok Lifeways, San Francisco, CA, USA. ${ }^{6}$ Division of General Internal Medicine, University of California at San Francisco, San Francisco, CA, USA. 7VA Quality Scholars Fellowship Senior Scholar, Geriatrics and Extended Care, San Francisco VA Medical Center, San Francisco, CA, USA.

Received: 5 August 2014 Accepted: 11 December 2014

Published: 16 December 2014

\section{References}

1. Du Moulin MF, Hamers JP, Ambergen AW, Janssen MA, Halfens RJ: Prevalence of urinary incontinence among community-dwelling adults receiving home care. Res Nurs Health 2008, 31(6):604-612. 
2. Markland AD, Richter HE, Fwu CW, Eggers P, Kusek JW: Prevalence and trends of urinary incontinence in adults in the United States, 2001 to 2008. J Urol 2011, 186(2):589-593.

3. Boyington JE, Howard DL, Carter-Edwards L, Gooden KM, Erdem N, Jallah Y, Busby-Whitehead J: Differences in resident characteristics and prevalence of urinary incontinence in nursing homes in the southeastern United States. Nurs Res 2007, 56(2):97-107.

4. Hawkins K, Pernarelli J, Ozminkowski RJ, Bai M, Gaston SJ, Hommer C, Migliori RJ, Yeh CS: The prevalence of urinary incontinence and its burden on the quality of life among older adults with medicare supplement insurance. Qual Life Res 2011, 20(5):723-732.

5. Aguilar-Navarro S, Navarrete-Reyes AP, Grados-Chavarria BH, Garcia-Lara JM, Amieva $\mathrm{H}$, Avila-Funes JA: The severity of urinary incontinence decreases health-related quality of life among community-dwelling elderly. J Gerontol A Biol Sci Med Sci 2012, 67(11):1266-1271.

6. Dubeau CE, Simon SE, Morris JN: The effect of urinary incontinence on quality of life in older nursing home residents. J Am Geriatr Soc 2006, 54(9):1325-1333.

7. Khatutsky G, Walsh EG, Brown DW: Urinary incontinence, functional status, and health-related quality of life among Medicare beneficiaries enrolled in the program for all-inclusive care for the elderly and dual eligible demonstration special needs plans. J Ambul Care Manage 2013, 36(1):35-49.

8. $\mathrm{Xu} \mathrm{D,} \mathrm{Kane} \mathrm{RL:} \mathrm{Effect} \mathrm{of} \mathrm{urinary} \mathrm{incontinence} \mathrm{on} \mathrm{older} \mathrm{nursing}$ home residents' self-reported quality of life. J Am Geriatr Soc 2013, 61(9):1473-1481

9. Dugan E, Cohen SJ, Bland DR, Preisser JS, Davis CC, Suggs PK, McGann P. The association of depressive symptoms and urinary incontinence among older adults. J Am Geriatr Soc 2000, 48(4):413-416.

10. Johnson TM 2nd, Kincade JE, Bernard SL, Busby-Whitehead J, Hertz-Picciotto I, DeFriese GH: The association of urinary incontinence with poor selfrated health. J Am Geriatr Soc 1998, 46(6):693-699.

11. Brown JS, Vittinghoff E, Wyman JF, Stone KL, Nevitt MC, Ensrud KE, Grady D: Urinary incontinence: does it increase risk for falls and fractures? Study of Osteoporotic Fractures Research Group. J Am Geriatr Soc 2000, 48(7):721-725

12. Damian J, Pastor-Barriuso R, Valderrama-Gama E, de Pedro-Cuesta J: Factors associated with falls among older adults living in institutions. BMC Geriatr 2013, 13:6-2318-13-6.

13. Thom DH, Haan MN, Van Den Eeden SK: Medically recognized urinary incontinence and risks of hospitalization, nursing home admission and mortality. Age Ageing 1997, 26(5):367-374.

14. John G, Gerstel E, Jung M, Dallenbach P, Faltin D, Petoud V, Zumwald C, Rutschmann OT: Urinary incontinence as a marker of higher mortality in patients receiving home care services. BJU Int 2014, 113(1):113-119.

15. Lawrence JM, Lukacz ES, Liu IL, Nager CW, Luber KM: Pelvic floor disorders, diabetes, and obesity in women: findings from the Kaiser Permanente Continence Associated Risk Epidemiology Study. Diabetes Care 2007 30(10):2536-2541.

16. Danforth KN, Townsend MK, Curhan GC, Resnick NM, Grodstein F: Type 2 diabetes mellitus and risk of stress, urge and mixed urinary incontinence. J Urol 2009, 181(1):193-197.

17. Izci Y, Topsever P, Filiz TM, Cinar ND, Uludag C, Lagro-Janssen T: The association between diabetes mellitus and urinary incontinence in adult women. Int Urogynecol J Pelvic Floor Dysfunct 2009, 20(8):947-952.

18. Lewis CM, Schrader R, Many A, Mackay M, Rogers RG: Diabetes and urinary incontinence in 50- to 90-year-old women: a cross-sectional populationbased study. Am J Obstet Gynecol 2005, 193(6):2154-2158.

19. Jackson SL, Scholes D, Boyko EJ, Abraham L, Fihn SD: Predictors of urinary incontinence in a prospective cohort of postmenopausal women. Obstet Gynecol 2006, 108(4):855-862

20. Lifford KL, Curhan GC, Hu FB, Barbieri RL, Grodstein F: Type 2 diabetes mellitus and risk of developing urinary incontinence. J Am Geriatr SoC 2005, 53(11):1851-1857.

21. Lee $P G$, Cigolle C, Blaum C: The co-occurrence of chronic diseases and geriatric syndromes: the health and retirement study. J Am Geriatr Soc 2009, 57(3):511-516.

22. Cigolle CT, Langa KM, Kabeto MU, Tian Z, Blaum CS: Geriatric conditions and disability: the health and retirement study. Ann Intern Med 2007 147(3):156-164.
23. Burti JS, Santos AM, Pereira RM, Zambon JP, Marques AP: Prevalence and clinical characteristics of urinary incontinence in elderly individuals of a low income. Arch Gerontol Geriatr 2012, 54(2):e42-e46.

24. American Geriatrics Society Expert Panel on Care of Older Adults with Diabetes Mellitus, Moreno G, Mangione CM, Kimbro L, Vaisberg E: Guidelines abstracted from the American Geriatrics Society guidelines for improving the care of older adults with diabetes mellitus: 2013 update. J Am Geriatr Soc 2013, 61(11):2020-2026.

25. Devore EE, Townsend MK, Resnick NM, Grodstein F: The epidemiology of urinary incontinence in women with type 2 diabetes. J Urol 2012, 188(5):1816-1821.

26. Diokno AC, Brown MB, Herzog AR: Relationship between use of diuretics and continence status in the elderly. Urology 1991, 38(1):39-42.

27. Ekundayo OJ, Markland A, Lefante C, Sui X, Goode PS, Allman RM, Ali M, Wahle C, Thornton PL, Ahmed A: Association of diuretic use and overactive bladder syndrome in older adults: a propensity score analysis. Arch Gerontol Geriatr 2009, 49(1):64-68.

28. Araki A, Ito H: Diabetes mellitus and geriatric syndromes. Geriatr Gerontol Int 2009, 9(2):105-114

29. Ouslander JG: Management of overactive bladder. N Engl J Med 2004, 350(8):786-799.

30. Vischer UM, Bauduceau B, Bourdel-Marchasson I, Blickle JF, Constans T, Fagot-Campagna A, Kaloustian E, Lassman-Vague V, Lecomte P, Simon D, Tessier D, Verny C, Doucet J, Alfediam/SFGG French-speaking group for study of diabetes in the elderly: A call to incorporate the prevention and treatment of geriatric disorders in the management of diabetes in the elderly. Diabetes Metab 2009, 35(3):168-177.

31. Jackson SL, Scholes D, Boyko E, Abraham L, Fihn SD: Urinary incontinence and diabetes in postmenopausal women. Diabetes Care 2005, 28(7):1730-1738.

32. Lee SJ, Karter AJ, Thai JN, Van Den Eeden SK, Huang ES: Glycemic control and urinary incontinence in women with diabetes mellitus. J Womens Health (Larchmt) 2013, 22(12):1049-1055.

33. Morrisroe SN, Rodriguez LV, Wang P, Smith AL, Trejo L, Sarkisian CA: Correlates of 1-year incidence of urinary incontinence in older Latino adults enrolled in a community-based physical activity trial. J Am Geriat Soc 2014, 62:740-746.

34. Landi F, Cesari M, Russo A, Onder G, Lattanzio F, Bernabei R, Silvernet-HC Study Group: Potentially reversible risk factors and urinary incontinence in frail older people living in community. Age Ageing 2003, 32(2):194-199.

35. De Gagne JC, So A, Oh J, Park S, Palmer MH: Sociodemographic and health indicators of older women with urinary incontinence: 2010 National Survey of Residential Care Facilities. J Am Geriatr Soc 2013, 61(6):981-986

36. Wieland D, Lamb V, Wang H, Sutton S, Eleazer GP, Egbert J: Participants in the Program of All-Inclusive Care for the Elderly (PACE) demonstration: developing disease-impairment-disability profiles. Gerontologist 2000, 40(2):218-227

\section{doi:10.1186/1471-2318-14-137}

Cite this article as: Hsu et al:: Predictors of urinary incontinence in community-dwelling frail older adults with diabetes mellitus in a cross-sectional study. BMC Geriatrics 2014 14:137.

\section{Submit your next manuscript to BioMed Central and take full advantage of:}

- Convenient online submission

- Thorough peer review

- No space constraints or color figure charges

- Immediate publication on acceptance

- Inclusion in PubMed, CAS, Scopus and Google Scholar

- Research which is freely available for redistribution 